\title{
FAKTOR YANG MEMENGARUHI KINERJA PEGAWAI (Studi Kasus Pada Kantor Kementerian Agama Kota Padangsidimpuan)
}

\author{
Damri Batubara \\ Institut Agama Islam Negeri Padangsidimpuan \\ Jalan T. Rizal Nurdin Km. 4,5 Sihitang, Padangsidimpuan \\ Email: damri.batubara1234@gmail.com
}

\begin{abstract}
Abstrak,
Kinerja pegawai pada Kantor Kementerian Agama Kota Padangsidimpuan masih sangat rendah, gejala yang kurang baik. Seperti, penyelesaian tugas yang tidak sesuai dengan target dan tidak tepat waktu, kualitas kerja yang kurang maksimal, menghambat kerja, serta rendahnya tanggungjawab dalam penyelesaian tugas. Maka salah satu faktor yang mempengaruhi kinerja pegawai salah satunya adalah teknologi informasi, pemanfaatan teknologi informasi bukan lagi merupakan kemewahan tapi keharusan. Sebab itu, perlu dilihat apakah ada pengaruh sistem informasi manajemen terhadap kinerja pegawai pada Kantor Kementerian Agama Kota Padangsidimpuan. Penelitian ini merupakan penelitian kuantitatif, teknik pengumpulan datanya angket, analisisnya dengan bantuan SPSS 21. Hasil analisis menunjukkan bahwa terdapat perbedaan yang signifikan ( $\mathrm{H}_{\mathrm{a}}$ diterima) dibuktikan dengan nilai t hitung $>\mathrm{t}$ table $=2,194>2,098$ kemudian dari perhitungan koefisien determinasi sebesar 0,376 yang artinya sebesar 37,6\% menunjukkan bahwa variable system informasi manajemen berpengaruh terhadap kinerja pegawai pada Kantor Kementerian Agama Kota Padangsidimpuan. Sedangkan sisanya 62,4\% dipengaruhi oleh paktor lain.
\end{abstract}

Kata Kunci : Sistem Informasi Manajemen, Kinerja, Pegawai

\begin{abstract}
Abstrak,
The performance of employees at the Ministry of Religion Office in Padangsidimpuan City is still very low, the symptoms are not good. Such as, the completion of tasks that are not in accordance with the target and not on time, the quality of work that is less than optimal, inhibits work, and low responsibility in the completion of tasks. So one of the factors that influence employee performance is information technology, the use of information technology is no longer a luxury but a necessity. Therefore, it needs to be seen whether there is an influence of the management information system on the performance of employees at the Ministry of Religion Office in Padangsidimpuan City. This research is a quantitative research, data collection techniques questionnaire, the analysis with the help of SPSS 21. The results of the analysis indicate that there are significant differences (Ha accepted) as evidenced by the value of t count> t table $=2.194>2.098$ then from the calculation of the coefficient of determination of 0.376 which means $37.6 \%$ indicated that the management information system variable affected the performance of employees at the Ministry of Religion Office in Padangsidimpuan City. While the remaining $62.4 \%$ is influenced by other pactors.
\end{abstract}

Keywords: Management Information System, Performance, Employees 
FAKTOR YANG MEMENGARUHI KINERJA PEGAWAI (Studi Kasus Pada Kantor Kementerian Agama Kota Padangsidimpuan)

Damri Batubara

\section{PENDAHULUAN}

Informasi dapat diibaratkan sebagai darah yang mengalir di dalam tubuh manusia, seperti halnya informasi di dalam sebuah kantor yang sangat penting untuk mendukung kalangsungan perkembangannya. Perkembangan teknologi informasi sekarang ini menuntut suatu dinas pemerintahan untuk mengikutinya agar semua aktifitas yang akan dilakukan menjadi cepat, hemat waktu dan akurat sehingga tujuan yang ingin dicapai lebih mudah direalisasikan. Teknologi informasi yang menyangkut kegunaan komputer dalam suatu dinas pemerintahan diharapkan dapat meningkatkan kinerja pegawai. Sebab, sistem informasi manajemen bertujuan menerima dan memproses data kemudian mengobahnya menjadi informasi yang berguana bagi para pengguna informasi dengan bentuk dan berjalannya sistem pemerosesan transaksi, baik spesialisasi informasi perusahaan maupun produsen komputer terus melanjutkan peningkatan dalam aktifitas komputasi sehingga mencapai aplikasi yang baru. (Yourself, 2007).

Dalam proses penentuan kinerja yang akan memandu aktifitas selanjutnya haruslah realistis, bisa dicapai dan spesifik agar menghasilkan tingkat kinerja yang baik. Apabila pegawai tidak memanfaatkan dengan semestinya, tidak bekerja dengan potensi yang penuh maka kinerja yang dihasilkan akan sangat rendah. Seperti kinerja pegawai Kantor Kementerian Agama Kota Padangsidimpuan. Terlihat ada beberapa gejala yang kurang baik. Seperti, tingkat kedisiplinan yang masih kurang, tugas-tugas yang sering terbengkalai, serta rendahnya rasa tanggungjawab dalam menyelesaikan pekerjaan (Pasaribu, 2016).

Ada beberapa faktor yang mempengaruhi kinerja pegawai, salah satunya pemanfaatan teknologi informasi, teknologi informasi bukan lagi kemewahan tapi keharusan. Keuntungan bagi kantor dengan adanya perkembangan teknologi informasi ini, yaitu manajemen informasi yang lebih handal, terstruktur, fleksibel untuk memaksimalkan visi dan misi kantor dan juga sangat bermanfaat untuk membantu dan memperlancar penyelesaian tugas dan kinerja pegawai lancar dan dapat ditingkatkan. Berdasarkan latar belakang tersebut, peneliti mengambil tema tentang Faktor Yang Memengaruhi Kinerja Pegawai (Studi Kasus Pada Kantor Kementerian Agama Kota Padangsidimpuan).

\section{TINJAUAN TEORITIK}

\section{Pengertian sistem informasi manajemen}

Sistem informasi terutama banyak berhubungan dengan kegiatan manajemen dalam dalam pengambilan keputusan tersebut, karena dengan adanya sistem informasi manajemen akan mengurangi keraguan manajer dalam pengambilan keputusan untuk memecahkan masalah yang akan dihadapi (Jr, 2009). 
Informasi merupakan data atau fakta yang telah diproses sedemikian rupa, sehingga berubah bentuknya menjadi informasi. Informasi dapat memperkaya penyajian dan mengungkapkan sesuatu yang penerimanya tidak tersangka, disamping itu informasi dapat mengurangi ketidakpastian serta mempunyai nilai dalam keputusan karena dengan adanya informasi kita dapat memilih tindakan-tindakan dengan resiko yang paling kecil (Kenneth, 2005).

\section{Pengertian manajemen}

Manajemen adalah suatu proses atau kerangka kerja, yang melibatkan bimbingan atau pengarahan suatu kelompok orang-orang kearah tujuan-tujuan organisasional atau maksudmaksud yang nyata (Kadir, 2003). Fungsi-fungsi manajemen yang terdiri dari:

1). Planning adalah menemukan tujuan-tujuan yang hendak dicapai selama suatu masa yang akan datang dan apa yang harus diperbuat agar dapat mencapai tujuan-tujuan itu.

2). Organizing adalah mengelompokkan dan menentukan berbagai kegiatan penting dan memberikan kekuasaan untuk melaksanakan kegiatan-kegiatan itu.

3). Staffing adalah menentukan keperluan-keperluan sumber daya manusia, pengarahan, penyaringan, latihan dan pengembangan tenaga kerja

4). Motivating adalah mengarahkan atau menyalurkan prilaku manusia kearah tujuan-tujuan

5). Controlling adalah mengukur pelaksanaan dengan tujuan-tujuan menentuakan sebabsebab penyimpangan-penyimpangan dan mengambil tindakan-tindakan korektif dimana perlu (George, 2005).

\section{Sistem Informasi Manajemen dalam Perspektif Islam}

Jauh sebelum diciptakan alam semesta ini, Allah sudah mengajarkan manajemen proses penciptaan alam. Langit dan bumi serta isinya bukanlah diciptakan sekaligus, tapi melalui manajemen yang sudah terukur selama 7 hari. Terbukti ahli teknologi astronomi ketika meneliti penciptaan planet yang ada diruang angkasa, melihat keteraturannya dan keterukurannya yang satu dengan yang lainnya tidak tabrakan menunjukkan adanya manajemen yang baik dalam penciptaannya (Deni, 2009).

Demikianlah Allah mengabadilan manajemen yang sempurna dalam al-Quran surah yunus ayat 3 , yang berbunyi: 


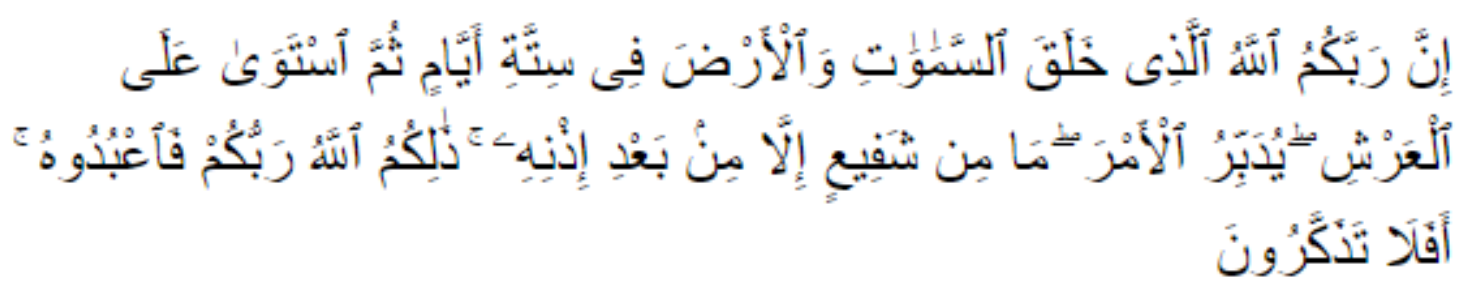

Artinya: "Sesungguhnya Tuhan kamu ialah Allah yang menciptakan langit dan bumi dalam enam masa, kemudian Dia bersemayam di atas 'Arsy untuk mengatur segala urusan. tiada seorangpun yang akan memberi syafa'at kecuali sesudah ada izin-Nya. (Dzat) yang demikian Itulah Allah, Tuhan kamu, Maka sembahlah Dia. Maka Apakah kamu tidak mengambil pelajaran”.

Ayat tersebut menjelaskan proses awal penciptaan alam sejak 14 abad lalu, ketika teknologi belum menunjang penelitian astronomi dan bahwa sang pencipta wahyu. Rasulullah SAW bahkan tidak mengenal baca tulis. Teori tersebut menjelaskan semesta bermula dari semua benda seukuran bola, pada masa o detik atau sebelumnya semua ada (Dani, 2009).

\section{Faktor-faktor dalam Penerapan Sistem Informasi Manajemen}

Suatau aplikasi sistem informasi bisa dievaluasi menurut tiga faktor. Yaitu, teknis, operasional dan ekonomi. Untuk aplikasi dalam penerapan ini disebut pengukuran kelayakan atas faktor tersebut, untuk aplikasi yang sedang berjalan evaluasi faktor merupakan ukuran hasil karya. Pengusulan yang baru harus tunduk pada tiga faktor di atas, yang berarti harus mengadakan perhitungan secara menyeluruh yang meliputi permasalahan teknis, pengusulan pertimbangan atas masalah yang menyangkut segi operasional serta dikaitkan dengan perhitungan ekonomisnya (Hamzah, 2011).

\section{Pengertian Kinerja Pegawai}

Kinerja adalah hasil kerja yang dicapai oleh seseorang atau sekelompok orang dalam suatu organisasi, sesuai dengan wewenang dan tanggungjawab masing-masing, dalam rangka upaya mencapai tujuan organisasi bersangkutan secara illegal, tidak melanggar hukum sesuai dengan moral dan realita dan etika, untuk meningkatkan efisiensi dan efektivitas sistem informasi manajemen, maka tidak akan terlepas dari perbaiki sistem secara keseluruhan, yakni pengelolaan kerja (Prestasi kerja) yang dicapai seseorang (R. Wayne, 2008).

\section{Kinerja Pegawai Dalam Perspektif Islam}


Dalam al-Quran Bekerja propesional merupakan perintah Allah yang harus dilakukan semaksimal mungkin tanpa ada rasa keputus asaan, baik itu kerja dalam berbisnis maupun pekerjaan yang diamanahkan pemerintah. Demikian firman Allah dalam al-Quran surah AtTaubah ayat 105 yang berbunyi:

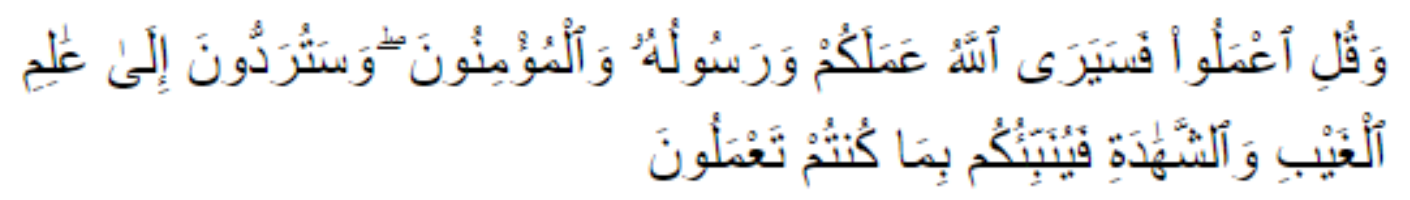

Artinya: "Katakanlah: "Bekerjalah kamu, Maka Allah dan Rasul-Nya serta orang-orang mukmin akan melihat pekerjaanmu itu, dan kamu akan dikembalikan kepada (Allah) yang mengetahui akan yang ghaib dan yang nyata, lalu diberitakan-Nya kepada kamu apa yang telah kamu kerjakan”.

Ayat ini menjelaskan bahwa setiap ummat Islam diperintahkan untuk bekerja keras, sehingga menjadi ummat yang mampu lebih unggul dibandingkan dengan ummat yang lainnya. Sehingga ummat Islam mampu menyelamatkan dirinya sendiri dan membantu ummat Islam yang lemah baik dari segi ekonominya maupun dari segi yang lainnya (Ahmad, 2002).

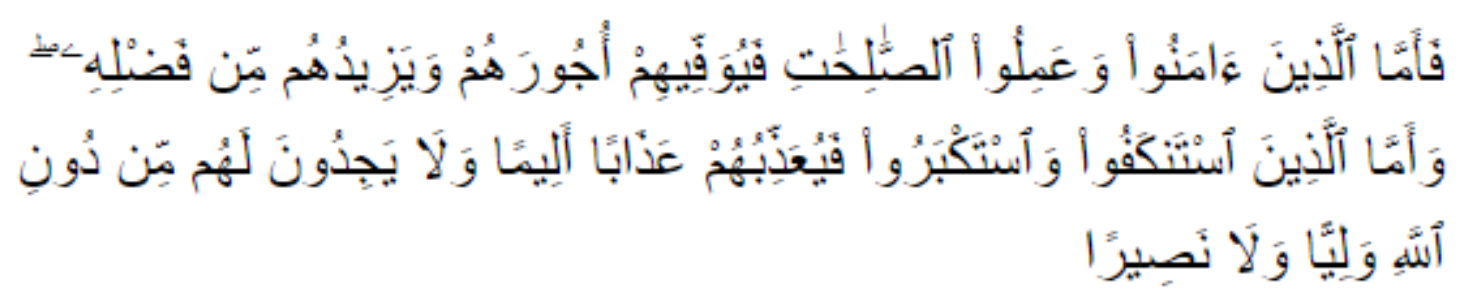

Artinya:"Adapun orang-orang yang beriman dan berbuat amal saleh, Maka Allah akan menyempurnakan pahala mereka dan menambah untuk mereka sebagian dari karuniaNya. Adapun orang-orang yang enggan dan menyombongkan diri, Maka Allah akan menyiksa mereka dengan siksaan yang pedih, dan mereka tidak akan memperoleh bagi diri mereka, pelindung dan penolong selain dari pada Allah" (An-nisa: 173).

Ayat tersebut menjelaskan dalam Islam seseorang yang diberi amanah harus menunjukan kinerja yang baik disebut dengan amal shaleh. Karena itu, diperlukan kesungguhan ketekunan dalam mengerjakan pekerjaan (Hani, 2001).

\section{METODE PENELITIAN}

\section{Jenis penelitian}


FAKTOR YANG MEMENGARUHI KINERJA PEGAWAI (Studi Kasus Pada Kantor Kementerian Agama Kota Padangsidimpuan)

Penelitian ini adalah penelitian kuantitatif dengan pendekatan deskriftif. Metode ini disebut kuantitatif karena data penelitian berupa angka-angka dan analisis menggunakan statistik SPSS 21 (Morissan, 2012).

\section{Populasi dan sampel}

Populasi dalam penelitian ini adalah seluruh pegawai yang ada di Kantor Kementerian Agama Padangsidimpuan sebanyak 38 orang. Sedangkan sampelnya peneliti berpedoman pada pendapat Suharsimi Arikunto, jika subjek lebih dari 100 orang dapat diambil 10-25\%, bila kurang dari 100 maka sampelnya keseluruhan subjeknya (Arikunto, 2006). Maka sampelnya keseluruhan pegawai yang ada di Kantor Kementerian Agama Padangsidimpuan sebanyak 38 pegawai.

\section{Teknik Pengolahan Dan Analisa Data}

Teknik pengolahan data dalam penelitian ini diolah melalui aplikasi SPSS 21 dengan melakukan beberapa pengujian

\section{Uji Validitas}

Uji Validitas adalah uji instrumen data untuk mengetahui seberapa cermat suatu item dalam mengukur apa yang ingin di ukur. Item dapat dikatan valid jika adanya korelasi yang signifikan dengan skor totalnya. Hal ini menunjukkan adanya dukungan item tersebut dalam mengungkap suatu yang ingin diungkap. Item berupa pertanyaan yang ditujukan kepada responden dengan menggunakan bentuk kuesioner.

\section{Uji Reliabilitas}

Uji reliabilitas digunakan untuk mengetahui konsistensi alat ukur yang biasanya menggunakan kuesioner. Maksudnya apakah alat ukur tersebut akan mendapatkan pengukuran yang tetap konsisten jika pengukuran diulang kemvbali.

\section{Teknik Analisis Data}

Analisis data diartikan sebagai upaya mengolah data menjadi informasi, sehingga karakteristik atau sipat-sipat data tersebut dapat mudah dipahami dan bermanfaat untuk menjawab masalah-masalah yang berkaitan dengan kegiatan penelitian. Tekniknya antara lain.

\section{Uji Normalitas}

Uji normalitas dilakukan untuk mengetahui apakah data yang diambil berasal dari populasi yang berdistribusi normal atau tidak. Teknik yang digunakan untuk menguji normalitas data antara lain dengan teknik kolmogrov-smirnov, yakni sama-sama menguji normalitas data yang disajikan secara individu (Noor, 2011). Dalam penelitian ini uji normalitas yang digunakan adalah uji K-S (Kolmogrov-Smirnov). 


\section{Analisis Regresi Sederhana}

Analisis regresi merupakan suatu analisis yang bertujuan untuk menunjukkan hubungan matematis antara variabel respons dan variabel penjelas (Setiawan, 2010). Analisis regresi digunakan untuk mengetahui bagaimana pengaruh variable dependen system informasi manajemen (X) terhadapa variabel dependen kinerja pegawai (Y) pada Kantor Kementerian Agama. Adapun bentuk persamaan regresi sederhana yang digunakan dalam penelitian ini sebagai berikut:

$$
\mathrm{KP}=\mathrm{a}+\mathrm{bSIM}
$$

Dimana

$$
\begin{array}{ll}
\mathrm{KP} & =\text { variabel kinerja pegawai } \\
\mathrm{SIM} & =\text { variabel sistem informasi manajemen } \\
\mathrm{a} & =\text { konstanta } \\
\mathrm{b} & =\text { koefisien regresi }
\end{array}
$$

\section{Uji Hipotesis (uji t)}

Uji t digunakan untuk mengetahui apakah variabel independen yaitu sistem informasi manajemen berpengaruh secara signifikan atau tidak terhadap variabel dependen yaitu kinerja pegawai. Untuk mengetahui hasil signifikan atau tidak, angka t-hitung akan dibandingkan dengan t-tabel. Maka digunakan tingkat signifikan o,05. Setelah diperoleh $t_{\text {hitung, maka untuk }}$ menginterprestasikan hasilnya berlaku ketentuan sebagai berikut:

Jika $t_{\text {hitung }}$ lebih besar dar $t_{\text {tabel, }}$ maka $\mathrm{H}_{\mathrm{O}}$ ditolak dan $\mathrm{H}_{\mathrm{a}}$ diterima, ini berarti pengaruh sistem informasi manajemen mempunyai pengaruh yang signifikan terhadap kinerja pegawai.

Jika $t_{\text {hitung }}$ lebih kecil dari $t_{\text {tabel, }}$ maka $\mathrm{H}_{\mathrm{O}}$ diterima dan $\mathrm{H}_{\mathrm{a}}$ ditolak, ini berarti pengaruh sistem informasi manajemen tidak berpengaruh terhadap kinerja pegawai.

\section{Uji R Square ( $\left.\mathbf{R}^{2}\right)$}

$\mathrm{R}$ Square $\left(\mathrm{R}^{2}\right)$ atau kuadrat dari $\mathrm{r}$, yaitu menunjukkan nilai koefisien determinasinya, angka ini akan diubah kedalam bentuk persen, peresentase sumbangan pengaruh variabel independen terhadap variabel dependen, maka digunakan tingkat signifikan 0,05. Pedoman untuk memberikan interprestasi koefisien korelasi (R) sebagai berikut (Priyatno, 2006):

$0,00-0,199=$ sangat rendah

$0,020-0,399=$ rendah

o,40 - 0,5999= sedang 
$0,60-0,799=$ kuat

$0,80-1,000=$ sangat kuat

\section{HASIL DAN PEMBAHASAN}

\section{Uji Validitas dan Realibilitas}

Dalam penelitian ini pengujian validitas menggunakan analisis Correlated Item-Total Correlation.

Tabel 1

Hasil analisis Correlated Item- Total Correlaton variable (X)

\begin{tabular}{|c|c|c|c|}
\hline $\begin{array}{c}\text { No. item } \\
\text { Pertanyaan }\end{array}$ & Nilai $r_{\text {hitung }}$ & Nilai $r_{\text {table }}$ & Interprestasi \\
\hline 1 & 0,349 & \multirow{10}{*}{$\begin{array}{c}\text { Instrument Valid, jika } \\
r_{\text {hitung }}>r_{\text {table }} \text { dengan } \\
\mathrm{N}=38 \text { Pada taraf } \\
\text { signifikan } 5 \% \\
\text { sehingga diperoleh } r\end{array}$} & Valid \\
\hline 2 & 0,590 & & Valid \\
\hline 3 & 0,513 & & Valid \\
\hline 4 & 0,474 & & Valid \\
\hline 5 & 0,499 & & Valid \\
\hline 6 & 0,525 & & Valid \\
\hline 7 & 0,348 & & Valid \\
\hline 8 & 0,423 & & Valid \\
\hline 9 & 0,532 & & Valid \\
\hline 10 & 0,548 & & Valid \\
\hline
\end{tabular}

Hasil penelitian: data diolah 2018

Dari tabel di atas didapat nilai korelasi antara skor item dengan skor total dilihat pada Correlated Item-Total Correlation yang telah disajikan dalam kolom $\mathbf{r}_{\text {hitung. Nilai ini kemudian }}$ dibandingkan dengan nilai $\mathrm{r}_{\text {tabel, }}$ yang dicari pada signifikan o,o5 dengan jumlah $(\mathrm{n})=38$, maka didapat $r_{\text {tabel }}$ sebesar 0,320. Berdasarkan hasil analisis didapat nilai korelasi untuk tiap-tiap item nilainya dari o,320, maka dapat disimpulkan item-item tersebut semuanya valid.

\section{Hasil Uji Validitas Variabel Kinerja Pegawai (Y)}

Table 2

Hasil analisis Correlated Item-Total Correlation Variabel (Y)

\begin{tabular}{|c|c|c|c|}
\hline $\begin{array}{c}\text { No. item } \\
\text { Pertayaan }\end{array}$ & Nilai $\boldsymbol{r}_{\text {hitung }}$ & Nilai $\mathrm{r}_{\text {tabel }}$ & Interprestasi \\
\hline 1 & 0,644 & & Valid \\
\hline
\end{tabular}




\begin{tabular}{|c|c|c|c|}
\hline 2 & 0,578 & \multirow{14}{*}{$\begin{array}{c}\text { Instrument Valid, } \\
\text { jika } r \text { hitung }>r_{\text {tabel }} \\
\text { dengan } \mathrm{N}=38 \text { Pada } \\
\text { taraf signifikan } 5 \% \\
\text { sehingga diperoleh } \\
r_{\text {table }} \\
(0.320)\end{array}$} & Valid \\
\hline 3 & 0,558 & & Valid \\
\hline 4 & 0,633 & & Valid \\
\hline 5 & 0,581 & & Valid \\
\hline 6 & 0,639 & & Valid \\
\hline 7 & 0,632 & & Valid \\
\hline 8 & 0,593 & & Valid \\
\hline 9 & 0,598 & & Valid \\
\hline 10 & 0,572 & & Valid \\
\hline 11 & 0,518 & & Valid \\
\hline 12 & 0,484 & & Valid \\
\hline 13 & 0,647 & & Valid \\
\hline 14 & 0,360 & & Valid \\
\hline 15 & 0,332 & & Valid \\
\hline
\end{tabular}

Hasil penelitian: data diolah 2018

Dari tabel didapat nilai korelasi antara skor item dengan skor total dilihat pada

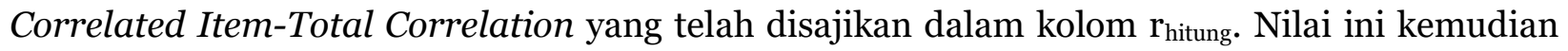
dibandingkan dengan nilai $r_{\text {tabel }}$ yang dicari pada signifikan 0,05 dengan jumlah $(n)=38$, maka didapat $r_{\text {tabel }}$ sebesar 0,320. Berdasarkan hasil analisis didapat nilai korelasi untuk tiap-tiap item nilainya dari o,320, maka dapat disimpulkan bahwa item-item tersebut valid.

\section{Uji Reliabilitas}

Uji reliabilitas digunakan untuk mengetahui tingkat keandalan atau dapat dikatan kepercayaan data yang dihasilkan oleh butiran instrument. Suatu variabel dapat dikatakan reliabilitas apabila nilai Cronbach ‘s Alpha>0,6.

\section{Hasil Uji Reliabilitas Variabel (X)}

\section{Tabel 3}


FAKTOR YANG MEMENGARUHI KINERJA PEGAWAI (Studi Kasus Pada Kantor Kementerian Agama Kota Padangsidimpuan)

Hasil Uji Reliabilitas pada Sistem Informasi Manajemen (X)

\begin{tabular}{|rr|rr|}
\hline \multicolumn{2}{|c|}{ Cronbach's Alpha } & N of items \\
\hline & .603 & & 10 \\
\hline
\end{tabular}

Hasil Penelitian: data diolah 2018

Berdasarkan tabel, uji reliabilitas angket sistem informasi manajemen yang terdapat pada lampiran, diperole Cronbach 's Alpha o,603, maka dapat disimpulkan bahwa butiran-butiran instrument penelitian adalah reliable.

Hasil Uji Reliabilitas Variabel (Y)

Tabel 4

Hasil Uji Reliabilitas pada Kinerja Pegawai (Y)

\begin{tabular}{|lr|r|}
\hline \multicolumn{2}{|c|}{ Cronbach's Alpha } & N of items \\
\hline & .836 & 15 \\
\hline
\end{tabular}

Hasil Penelitian : data diolah 2018

Berdasarkan tabel uji reliabilitas angket system informasi manajemen yang terdapat pada lampiran, diperoleh Cronbach 's Alpha> 0,6, maka dapat disimpulkan butiran-butiran instrument penelitian adalah reliable.

\section{Uji Normalitas}

Apabila data menyebar disekitar garis diagonal dan mengikuti arah garis diagonal menunjukkan pola distribusi normal, maka model rekresi memenuhi asumsi normalitas dan apabila data menyebar jauh dari garis diagonal dan tidak mengikuti garis diagonal, tidak menunjukkan pola distribusi normal, maka model regresi tidak memenuhi asumsi normalitas. Selanjutnya apabila nilai kolmogrov smirnov $\mathrm{Z}$ adalah $>0,05$ maka data dikatakan sudah berdestribusi normal.

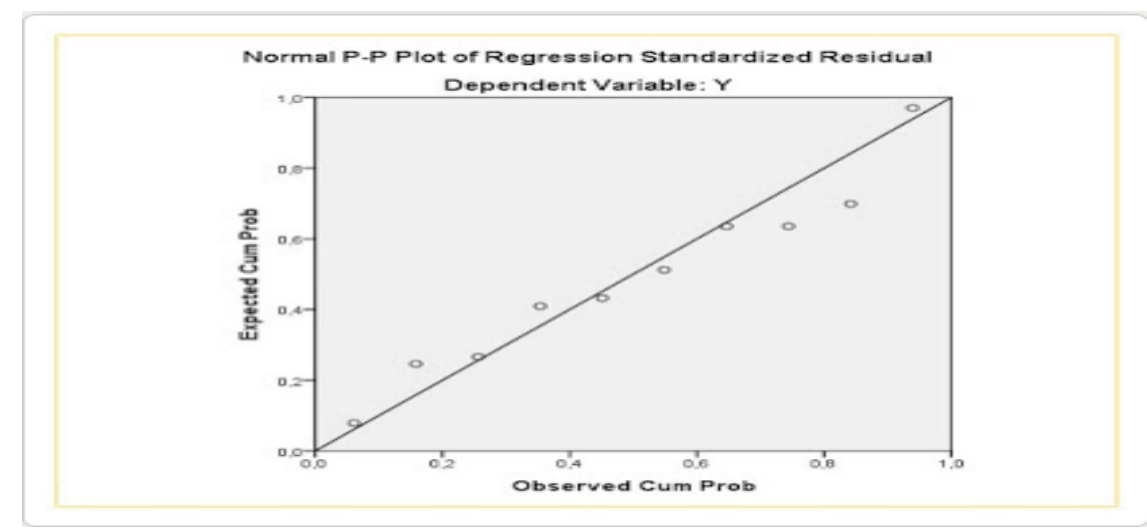

Gambar 1. Hasil Plot Uji Normalitas 
Dari gambar dapat diketahui bahwa titik-titik menyebar disekitar garis diagonal dan tidak ada yang menyebar jauh dari garis diagonal. Dengan demikian dapat disimpulkan bahwa data tersebut sudah normal.

Tabel 5.

Hasil One-Sampel Kolmogorov-smirnov One-Sampel Kolmogrov-smirnov Test

\begin{tabular}{|c|c|c|}
\hline & $\begin{array}{c}\text { Sistem_informasi_ } \\
\text { manajemen }\end{array}$ & Kinerja_pegawai \\
\hline $\mathrm{N}$ & 10 & 16 \\
\hline Normal Mean & 173.50 & 170.00 \\
\hline Parameters $^{\text {a.b }}$ Std & 2.550 & 2.989 \\
\hline $\begin{array}{l}\text { Deviation } \\
\text { Absolute }\end{array}$ & .178 & .313 \\
\hline Most Extreme Positive & .137 & .189 \\
\hline Differences Negative & -.178 & -.313 \\
\hline Kolmogorov-Smirnov Z & .562 & 1.250 \\
\hline Asymp.sig. (2-tailed) & .910 & .088 \\
\hline
\end{tabular}

a. Test Distribution is Normal.

b. Calculatet From date

Berdasarkan output hasil uji normalis, bahwa nilai p (Kolmogrov Smirnov Z) untuk variabel sistem informasi manajemen $(\mathrm{X})$ adalah 0,562 atau nilai signifikan > 0,05, sedangkan nilai p untuk variabel kinerja pegawai $(\mathrm{Y})$ adalah 1,250 atau nilai signifikan > 0,05, maka $\mathrm{H}_{\mathrm{O}}$ diterima. Dapat diartikan bahwa kedua variabel tersebut dinyatakan memenuhi asumsi normalitas karena telah memperoleh nilai $p$ yang lebih besar dari nilai o,05. Jadi dapat disimpulkan bahwa data sistem informasi manajemen berpengaruh terhadap kinerja pegawai.

\section{Analisis regresi Linear Sederhana}

Tabel 6.

\section{Hasil Analisis Regresi Linear Sederhana} Coefficients ${ }^{\mathbf{a}}$

\begin{tabular}{|c|c|c|c|c|c|}
\hline Model & \multicolumn{2}{|c|}{$\begin{array}{l}\text { Unstandardizet } \\
\text { Coefficients }\end{array}$} & $\begin{array}{l}\text { Standardizet } \\
\text { Cofficients }\end{array}$ & $\mathrm{t}$ & sig \\
\hline \multirow{2}{*}{$\begin{array}{l}\text { (Constant) } \\
1 \\
\text { Sistem_Infrmasi_ } \\
\text { Manajemen }\end{array}$} & B & $\begin{array}{l}\text { Std. } \\
\text { Error }\end{array}$ & Beta & & \\
\hline & $\begin{array}{l}303.279 \\
.761\end{array}$ & $\begin{array}{l}60.156 \\
.347\end{array}$ & .613. & $\begin{array}{l}5.025 \\
2.194\end{array}$ & $\begin{array}{l}.001 \\
.060\end{array}$ \\
\hline
\end{tabular}

a. dependen Variabel : kinerja_pegawai 
FAKTOR YANG MEMENGARUHI KINERJA PEGAWAI

Dari tabel di atas dapat dilihat pada kolom Ustandardizet Cofficients dan B menyatakan untuk nilai regresi dengan $\mathrm{a}=302,279$ dan $\mathrm{b}=0,761$ sehingga didapat persamaan:

$$
\begin{aligned}
& \mathrm{KP}=\mathrm{a}+\mathrm{bSIM} \\
& \mathrm{KP}=302,279+0,761 \mathrm{SIM}
\end{aligned}
$$

Berdasarkan persamaan tersebut dapat digambarkan sebagai berikut:

a) Konstanta (a) sebesar 302,279: artinya variable sistem informasi manajemen nilainya o satuan, maka kinerja pegawai yang terbentuk sebesar 302,279 satuan

b) Koefisien $\mathrm{X}(\mathrm{b})=0,761$. Kofesien regresi variabel independen terhadap variabel dependen sebesar 0,761. Hal tersebut mempunyai arti jika sistem informasi manajemen mengalami kenaikan 1 satuan, maka kinerja pegawai akan meningkat sebesar 0,761 satuan.

\section{Koefisiensi Determinasi $\left(\mathbf{R}^{2}\right)$}

\section{Tabel 7 \\ Hasil Analisis Koefisiensi Determinasi Model Summary ${ }^{b}$}

\begin{tabular}{|l|l|l|l|l|}
\hline Model & R & PR Square & Adjusted R Square & $\begin{array}{l}\text { Std. Error of the } \\
\text { Estimate }\end{array}$ \\
\hline 1 & $.613^{\mathrm{a}}$ & .376 & .298 & 2.652 \\
\hline
\end{tabular}

a. Predictors: (Constans), Sistem_informasi_manajemen

b. Dependen Variabel: Kinerja_Pegawai

sumber Penelitian, Data diolah 2018

Berdasarkan tabel di atas diperoleh nilai R² (R Square) sebesar 0,376 atau (37,6\%). Hal ini menunjukkan bahwa variasi variabel dependen dipengaruhi variabel independen sebesar 37,6\% atau memiliki model regresi bisa menjelaskan pengaruh variabel independen terhadap variasi variabel dependen sebesar 37,6\%. Sedangkan sisanya sebesar 62,4\% dipengaruhi oleh variabel lain yang tidak diteliti dalam penelitian ini.

\section{Uji Hipotesis (Uji t)}

Tabel 8

Hasil uji t Regresi Linear Sederhana Coefficients $^{\mathbf{a}}$

\begin{tabular}{|l|c|c|c|c|c|}
\hline Model & \multicolumn{2}{|c|}{$\begin{array}{c}\text { Unstandardized } \\
\text { Coefficients }\end{array}$} & $\begin{array}{c}\text { Standardized } \\
\text { Coefficients }\end{array}$ & Sig. \\
\cline { 2 - 3 } & B & Std. Error & Beta & & \\
\hline
\end{tabular}




\begin{tabular}{|l|r|r|r|r|r|}
\hline (Constant) & 302.279 & 60.156 & & 5.025 & .001 \\
Sistem_infor & .761 & .347 & .613 & 2.194 & .060 \\
masi_mana & & & & & \\
jemen & & & & & \\
\hline
\end{tabular}

a. Dependent Variabel: Kinerja_Pegawai

*Sumber Penelitian (Hasil output SPSS 21) Data diolah 2018

Pada tabel di atas terlihat bahwa uji t sebesar 2,194. Nilai uji t tersebut pada tarap signifikan $5 \%$ yang diperoleh dengan derajat kebebasan $(\mathrm{df})=\mathrm{n}-\mathrm{k}(38-2)$ sehingga diperoleh nilai

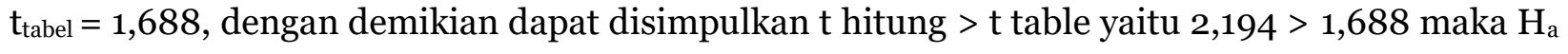
diterima, artinya sistem informasi manajemen berpengaruh terhadap kinerja pegawai studi kasus pada kantor kementerian agama kota padangsidimpuan.

\section{KESIMPULAN}

Berdasarkan hasil penelitian yang telah dilakukan sistem informasi manajemen memiliki pengaruh terhadap kinerja pegawai pada Kantor Kementerian Agama Kota Padangsidimpuan, hal ini dibuktikan dengan nilai t hitung $>\mathrm{t}$ table $=2,194>$ 1,688. Dari perhitungan koefisisen determinasi sebesar 0,376 yang memiliki arti bahwa model regresi bisa menjelaskan pengaruh variabel dependen sebesar 37,6 yang memiliki arti bahwa model regresi bisa menjelaskan pengaruh variabel independen terhadap variasi variabel dependen sebesar 37,6\% pada Kantor Kementerian Agama Kota Padangsidimpuan, sedang sisanya 62,4\% dijelaskan oleh faktor lain yang tidak dibahas dalam penelitian ini.

Selain itu hasil penelitian juga menunjukkan bahwa sistem informasi manajemen memberikan pengaruh yang signifikan terhadap kinerja pegawai pada Kantor Kementerian Agama Kota Padangsidimpuan, adanya pengaruh ini dapat dibuktikan dari besarnya persamaan regresinya, yaitu $\mathrm{KP}=302,279+\mathrm{O}, 761 \mathrm{SIM}$.

\section{DAFTAR PUSTAKA}

Agama, Departemen, 2004, Alquran dan Terjemahannya, Bandung : Jumanatul Ali Art.

Arikunto, Suharsimi, 2002, Prosedur Penelitian Suatu Pendekatan Praktik, Jakarta : Rineka Cipta.

B. Uno, Hamzah, 2011, Teknologi Komunikasi dan Informasi Pembelajaran, Jakarta : PT Bimi Aksara.

Darmawan, Deni, 2009, Informasi Manajemen, Yogyakarta : PT. Askara Bumi. 
Handono, Hani, 2001, Manajemen Porsonalia dan Sumber Daya Manusia, Yogyakarta : PT Indeks

Ibrahim, Ahmad, 2002, Manajemen Syariah, Jakarta : Raja Wali Pers.

Kadir, Abdul, 2003, Pengenalan sistem Informasi, Yogyakarta : Andi.

Kenneth dan Loudon, 2005, Sistem Informasi Manajemen, Jakarta : Jane P.

Kusrini, Dwi Endah dan Setiawan, 2010, Ekonometrika, Yogyakarta : Andi.

Morissan, 2012, Metode Penelitian Survei, Jakarta : PT Indeks.

Mondy, R. Wayne, 2008, Manajemen Sumber Daya Manusia, Jakarta : Erlangga.

McLeod Jr, Raymond dan P. Schell George, 2009, Sistem Informasi Manajemen, Jakarta : Salemba Empat

Noor, Juliansyah, 2011, Metodologi Penelitian. Jakarta : Prenada Media Group.

R Terry, George dan W. Rue, Leslie, 2005, Dasar-Dasar Manajemen, Jakarta : PT Bumi Aksara.

Yourself, Teach, Alpha, 2007, Manajement Skills, Jakarta : Prenada. 